\title{
Fifth metatarsal tuberosity avulsion fractures: a new surgical technique without metal implant
}

\author{
F.F. Sesti ${ }^{1}$, F. Oliva ${ }^{2}$, R. Iundusi ${ }^{1}$ \\ 1 Department of Musculoskeletal Disorders, University Tor Vergata, Rome, Italy \\ 2 Department of Musculoskeletal Disorders, School of Medicine and Surgery, University of Salerno, Salerno, Italy
}

\section{CORRESPONDING AUTHOR:}

Francesco Oliva

Department of Musculoskeletal Disorders, School of Medicine and Surgery,

University of Salerno,

Salerno, Italy

E-mail: olivafrancesco@hotmail.com

\section{DOI:}

10.32098/mltj.02.2019.12

LEVEL OF EVIDENCE:

5

\begin{abstract}
SUMMARY
Background: Lawrence and Botte classified in the 1993 the fractures of 5MTB in a Zone 1 (tuberosity avulsion fracture), Zone 2 (Jones fracture), and Zone 3 (stress diaphyseal fractures). Despite good outcomes with non-operative treatment, displacement, intra-articular involvement, comminution or painful non-union of Zone 1 fracture have been reported to benefit with early open reduction and fixation. We considered a Zone 1 fracture (tuberosity avulsion) with displacement of the segment from the metatarsal metaphysis $>2 \mathrm{~mm}$.

Surgical technique: We describe a surgical procedure for the tuberosity avulsion fractures (Zone 1 of Lawrence and Botte classification or type I-B of Mehlhorn classification) using FiberWire or Vycril sutures.

Conclusions: This technique, without using metal implant, provides a theoretically lower rate of infections, could be useful in patients referring metal allergy or hypersensitivity to metal implants and it is not necessary the fluoroscopic guidance.
\end{abstract}

\section{KEY WORDS}

Fifth Metatarsal Bone; Foot Fractures; Peroneus Brevis Tendon; Surgery.

\section{INTRODUCTION}

Fractures of the metatarsal bones are the most frequent injuries of the foot $(1,2)$ with an incidence of 67 per 100,000/ year. More than $70 \%$ involve the Fifth Metatarsal Bone $(3,4)$ (5MTB) and approximately $80 \%$ are located proximally. Proximal fractures of the 5MTB show more incidence of delayed union and non-union (5).

Several classifications have been published (Torg, Stewart) $(6,7)$ for the fifth metatarsal proximal fractures. The most used is the classification of Lawrence and Botte. It classified a Zone 1 (tuberosity avulsion fracture), Zone 2 (Jones fracture), and Zone 3 (stress diaphyseal fractures) (8) (Figure 1). More recently, Mehlhorn et al. (9) proposed a new radiographic classification, identifying three fracture groups at high risk of secondary displacement: fractures of the lateral third of the 5MTB, fractures occurring in the middle third, and fractures of the medial third. They further divided them into two categories: non-displaced or displaced with a fracture-step-off $>2 \mathrm{~mm}$ (Figure 2). Although Mehlhorn et al. evaluated the risk of secondary displacement, they did not evaluate patient clinical outcomes (10).

Treatment of 5MTB fractures can be challenging and is a problem still not solved at all.

Excluding the bone anatomy, soft tissue around the 5MTB appear complex, indeed muscle and tendon structures are very important in the biomechanics of this kind of fractures. Distal to the Peroneal Tubercle (Ptub), the Peroneus Brevis Tendon (PBT) runs directly to insert into the base of the 5MTB, and the Peroneus Longus Tendon (PLT) curves beneath the cuboid, to reach the plantar region, which is usually attached to the first and second metatarsals (11).

Has been described by Imre (12) anatomical variants of PBT and PLT insertions; regarding distal insertion of PBT Imre described six groups (Figure 3). 


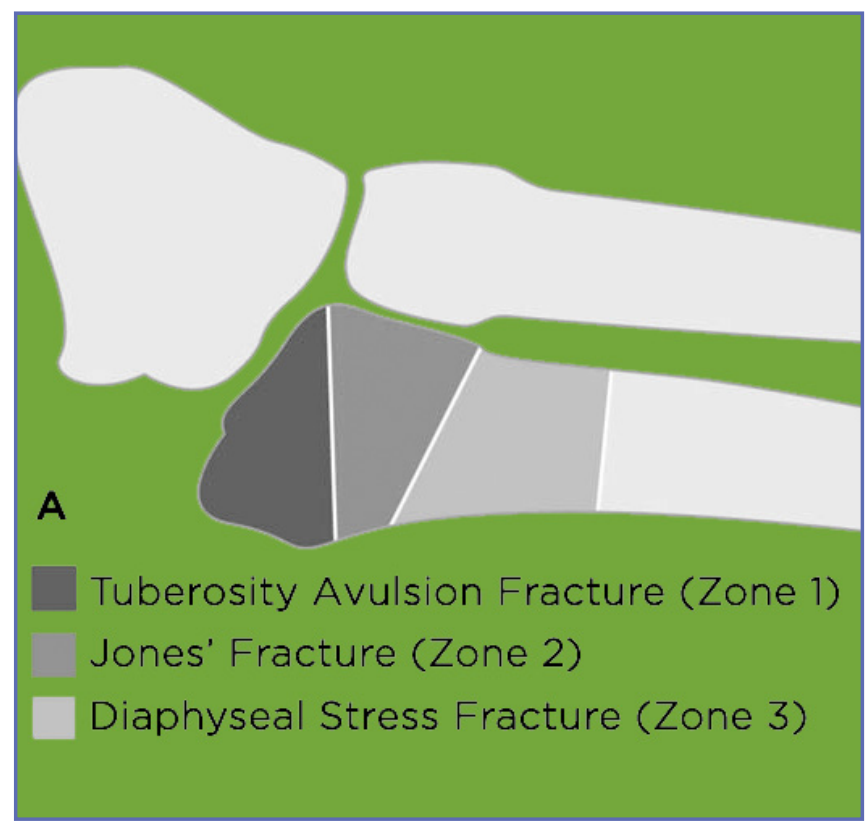

Figure 1. Lawrence and Botte classification. (Lawrence SJ, Foot Ankle. 1993).
Avulsion fractures of the tuberosity account for $45 \%$ to $93 \%$ of all fractures of the 5MTB. The high incidence of avulsion fractures may be caused by its association with inversion ankle sprains. Both the PBT and the lateral band of the plantar aponeurosis have been considered to cause avulsion of this fragment and other several traumatic injuries of soft tissue around during a rapid inversion of the rearfoot/ankle complex $(13,14)$.

\section{SURGICAL TECHNIQUE}

To describe our original surgical procedure, we show a case of the 5MTB (Zone $1 \mathrm{sec}$. Lawrence and Botte classification; Type I-B sec. Mehlhorn classification) (tuberosity avulsion) with displacement of the bone fragment from the metatarsal metaphysis $>2 \mathrm{~mm}$ in a female 56 year old injured her right midfoot during an accidental fall. She was seen by us in emergency care department and diagnosis was made with foot $\mathrm{X}$-rays in 3 standard views (Figure 4).

The patient refers a metal allergy and hypersensitivity to metallic implants and no further comorbidities. She decided, before adequate and specific informed consent, to be

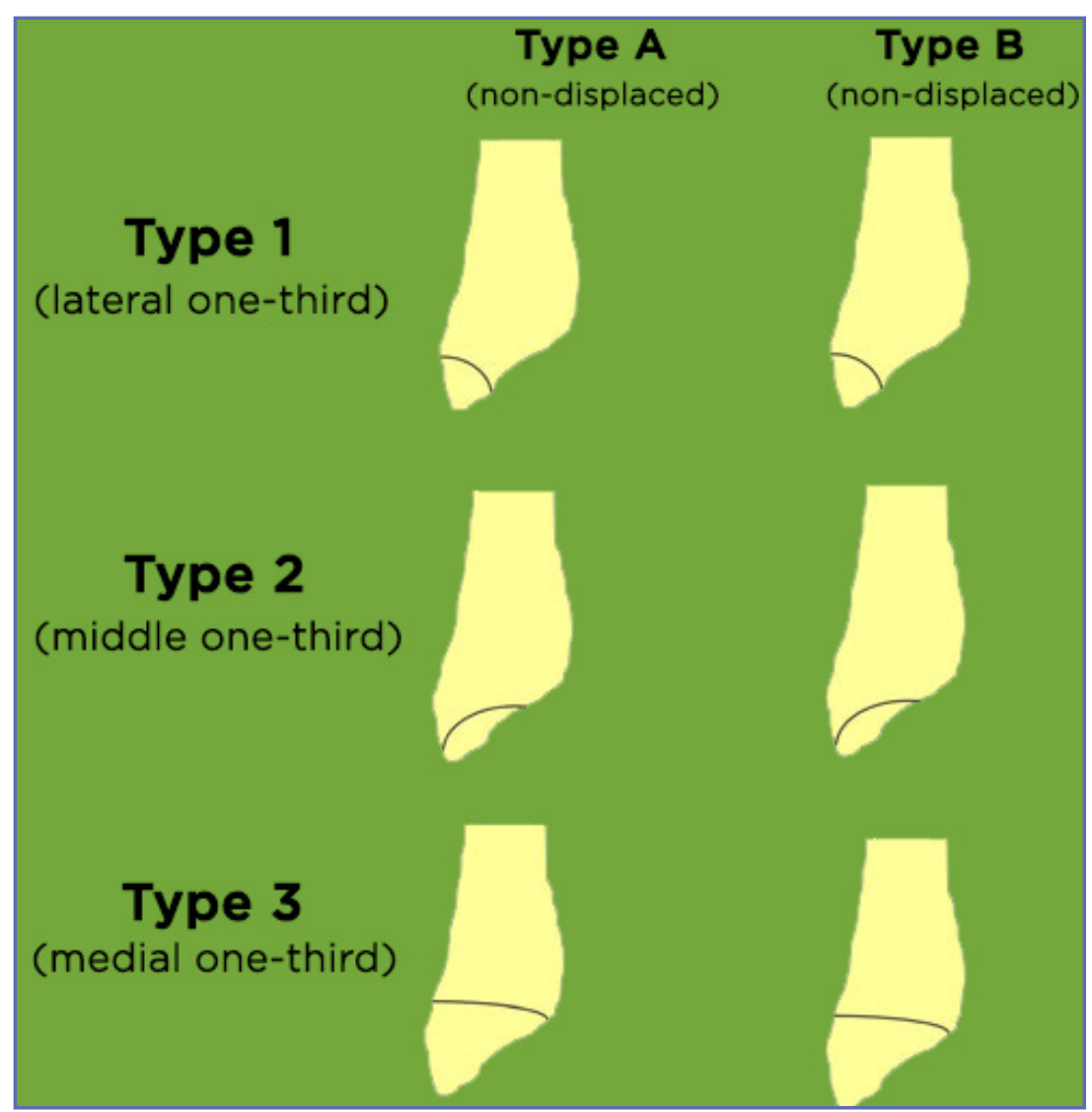

Figure 2. Mehlhorn classification: dependant on the joint entry of the fracture line at the fifth metatarsal base (lateral one-third, middle one-third, and medial one-third) type I, II, or III were defined. Fractures without displacement were summarized as A-type (I-IIIA) and with a fracture-step-off $>2 \mathrm{~mm}$ as B-type (I-IIIB) (7). (Mehlhorn A. et al. Skeletal Radiol. 2014). 


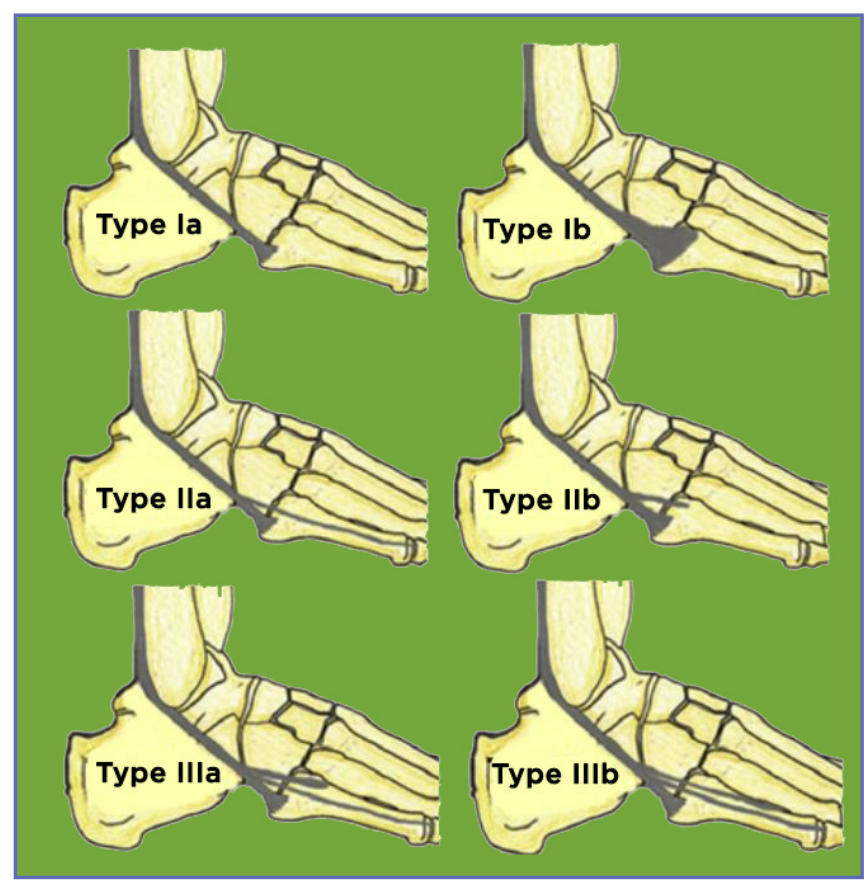

Figure 3. Classification of PB (Peroneus Brevis) insertion, as described by Imre (10).

(Imre N. Foot Ankle Surg. 2016).

submitted to the repair of her fracture the day after, without metal implant. The patient was placed in lateral position under general anaesthesia with a lower leg tourniquet inflated at $250 \mathrm{mmHg}$.

A lateral skin incision of $4 \mathrm{~cm}$ was centred at the base of the 5MTB. Accurate dissection of subcutaneous tissue was performed and hematoma of fracture was debrided. Periosteal tissue in the fracture site was gently dissected. An evident gap between the proximal fracture fragment and the $5 \mathrm{MTB}$ was observed due to the retraction of PBT (Figure 5). A drill-hole of $2 \mathrm{~mm}$ with a $\mathrm{K}$-wire was performed in the distal cortex of 5MTB. FiberWire (size 2, Arthrex ${ }^{\circledR}$ ) was passed through the distal cortex hole and crossed on the empty gap (Figure 6). FiberWire was passed $1 \mathrm{~cm}$ proximally the insertion of PBT with a single knot caring to reduce the gap when tightening the knot. Suturing the distal insertion of PBT we do not touch the small proximal fragment avoiding any further disruption, reaching an optimal reduction of the fracture. To reinforce the main suture, Vycril 0 can be used (Figure 7).

Post-operative X-ray was performed in standard views (Figure 8). Weight bearing was allowed the day after with a lower pneumatic leg brace (Walker, $\mathrm{DJO}^{\circledR}$ ). At six weeks another X-ray was request showing no displacement of the

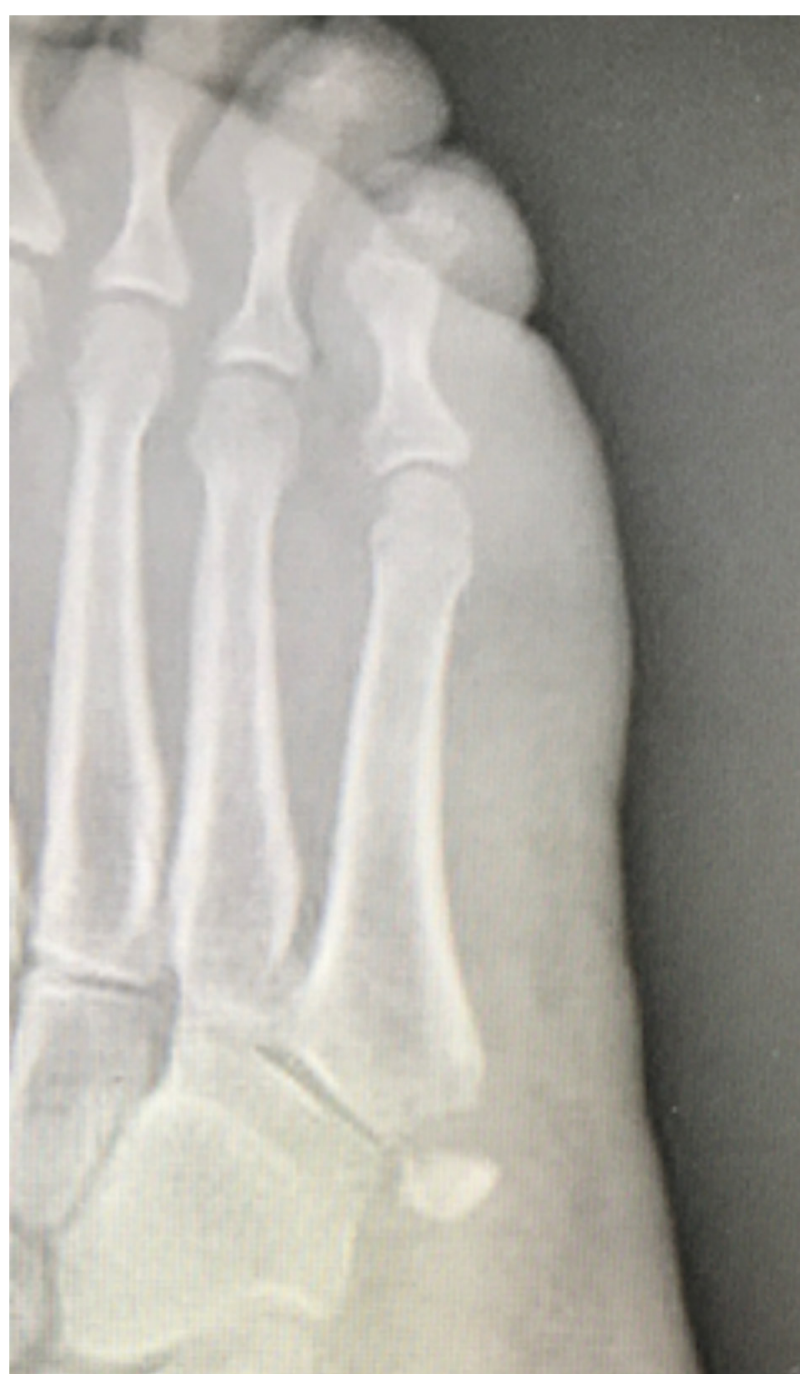

Figure 4. Pre-operative foot oblique projection X-ray shows Zone 1 fracture of Lawrence and Botte classification and Type I-B of Mehlhorn classification.

site of fracture and initial bony callus formation (Figure 9). The patient was allowed to remove the pneumatic leg brace and gentle passive kinesis was started. She does not refer any pain or discomfort. The patient refused X-ray when came at three months at our clinic because she refers to be back to all her previous daily activity.

\section{DISCUSSION}

Fractures of the 5MTB are frequently seen, commonly located to the proximal epiphysis. They can be treated conservatively with good results. Open reduction and internal fixation 


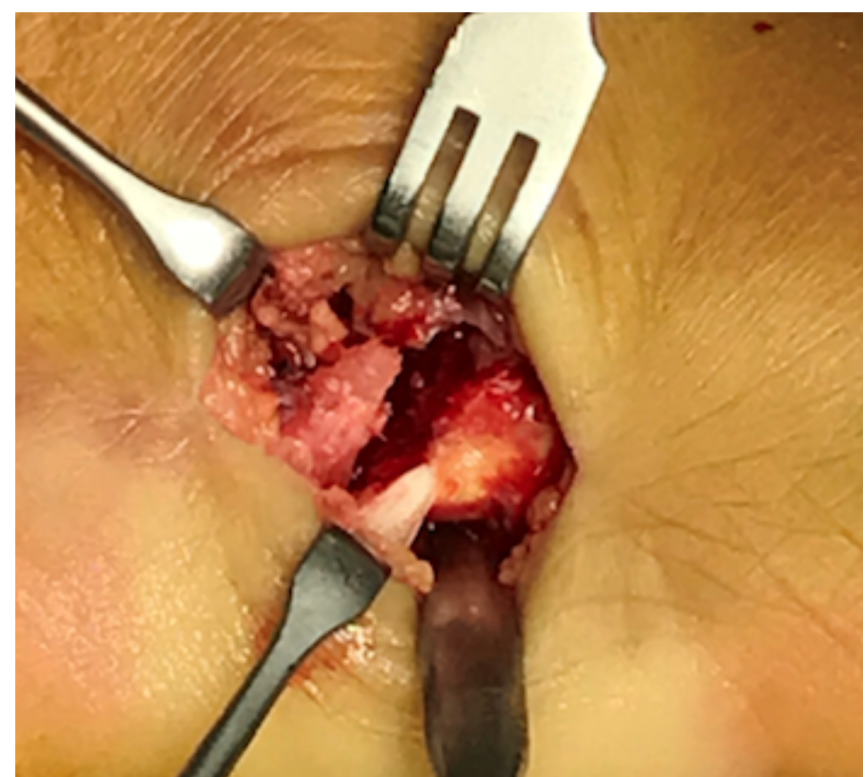

Figure 5. Intraoperative image shows the fracture and its displacement.

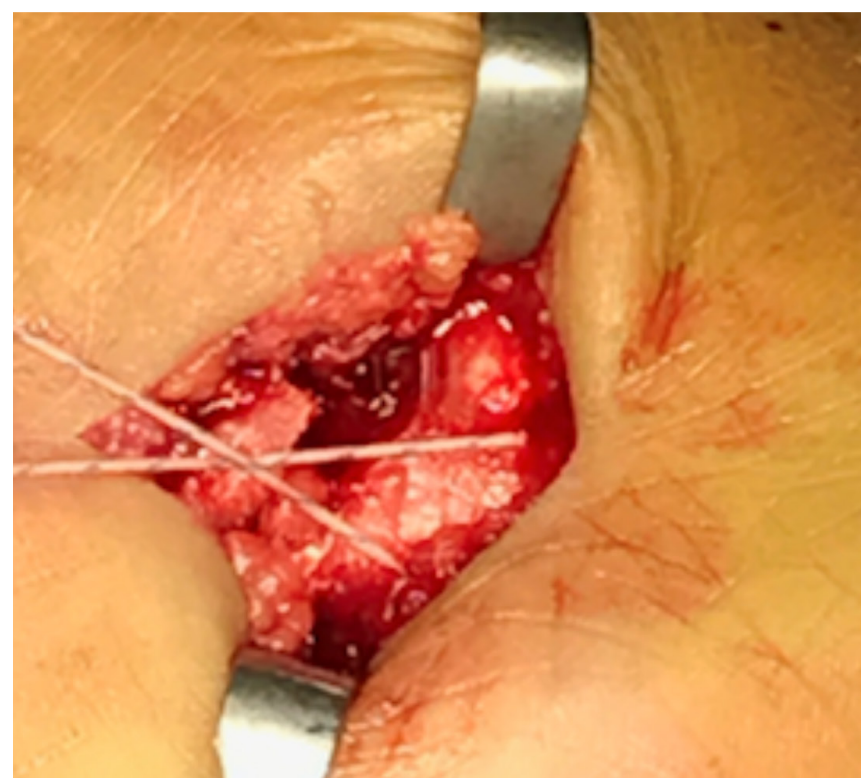

Figure 6. FiberWire passed through the distal fragment of the fracture.

is recommended for fractures displaced more than $2 \mathrm{~mm}$ or that involve more than $30 \%$ of the cuboidal joint $(15,16)$. Case series of fractures at the border between metaphyseal and diaphyseal proximal metatarsus, treated by modified Tension Band Wiring procedure has been described (17).

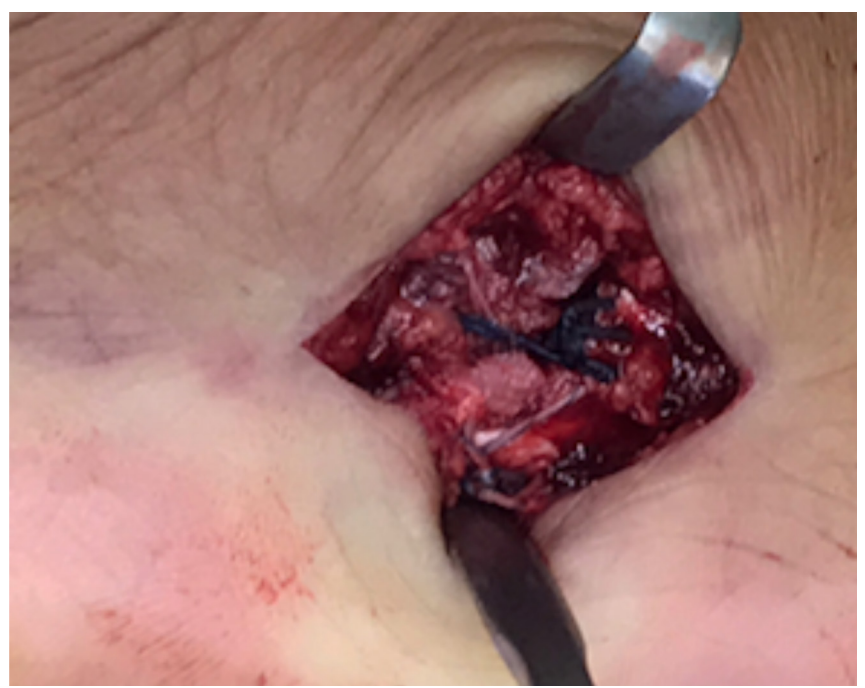

Figure 7. Intra-operative picture shows the obtained reduction of the fracture.

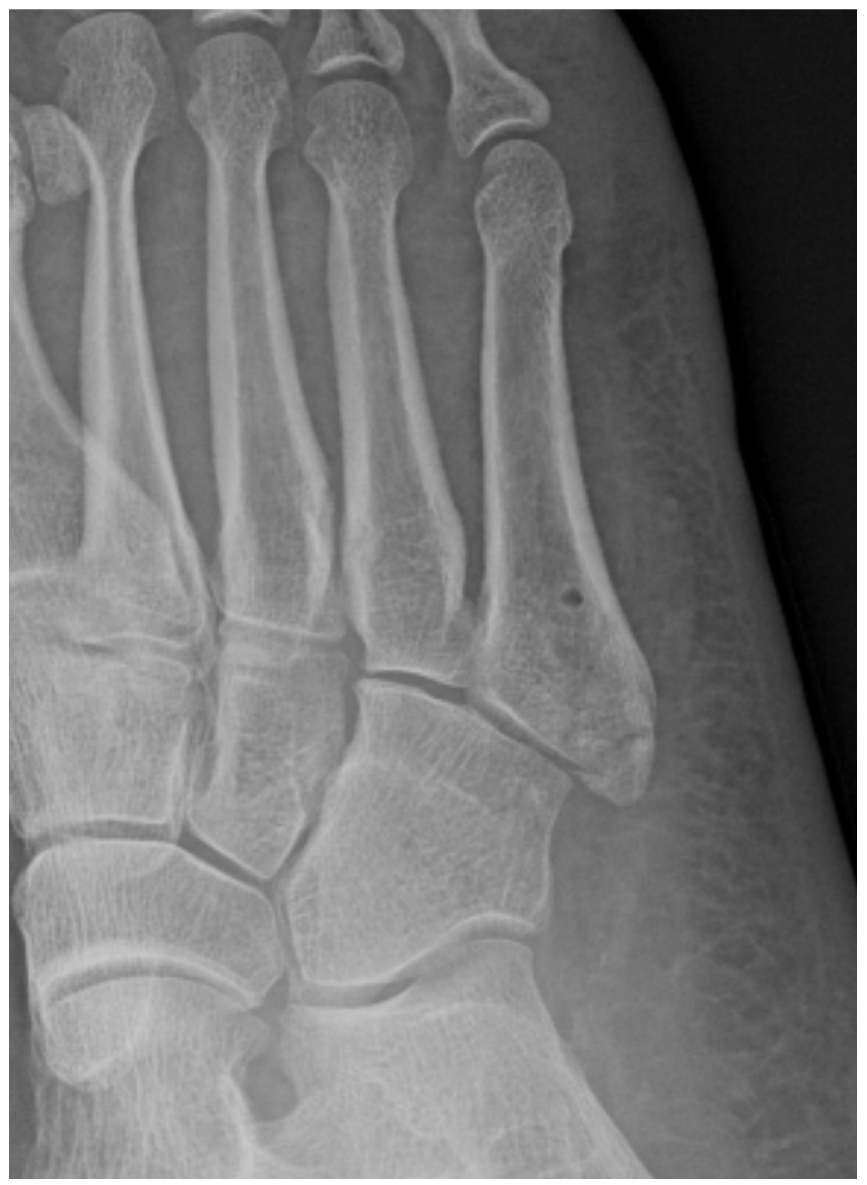

Figure 8. Post-operative $\mathrm{X}$-ray shows the obtained reduction without metal implant. It is possible to see the drilled hole where we passed the FiberWire. 
In those cases, fractures involved more frequently Zone 2 (metatarsal diaphysis/metaphysis border - Jones fracture) than more the proximal Zone 1 (tuberosity avulsion fracture). Our surgical procedure seems to be unique without using metallic implants; in our pilot experience provides encouraging excellent results with an acceptable reduction of the fracture. An open reduction and a suturing across the PBT distal insertion through a distal drilled hole in the distal cortex of the 5MTB, avoids the fluoroscopic guidance and a theoretically lower rate of deep bone infections. Furthermore, in the patients referring metal allergy or hypersensitivity to metal implants can be very useful. In all case treated we reached a complete healing of the fractures treated, allowing an immediate weight bearing. Although the postoperative follow-up is short and the indication is limited for selected patients, seems to us that this surgical procedure is a new and valid alternative, in according to the functional requirements of the patient and the type of fracture.

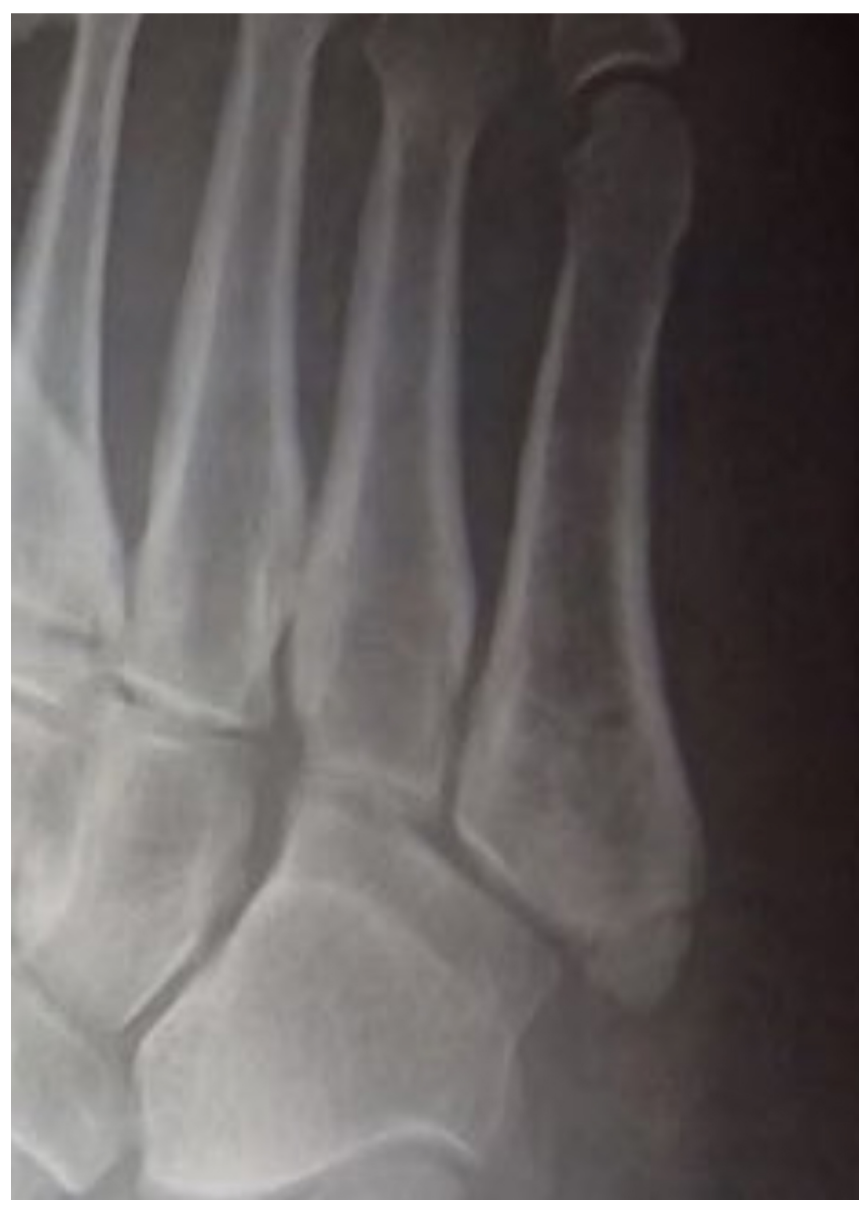

Figure 9. X-ray at 6 weeks after surgery shows non secondary displacement and initial bony callus formation.

\section{Conflict of Interest}

The authors declare that they have no conflict of interest (18)

\section{REFERENCES}

1. Polzer H, Polzer S, Mutschler W, Prall WC. Acute fractures to the proximal 5MTB: Development of classification and treatment recommendations based on the current evidence. Injury. 2012;10:1626-32.

2. Spector FC, Karlin JM, Scurran BL, Silvani SL. Lesser metatarsal fractures. Incidence, management, and review. J Am Podiatry Assoc. 1984;74(6):259-64.

3. Cakir H, Vliet-Koppert ST, Van Lieshout EM, De Vries MR, Van Der EM, Schepers T. Demographics and outcome of metatarsal fractures. Arch Orthop Trauma Surg. 2011;131(2):241-5.

4. Petrisor BA, Ekrol I, Court-Brown C. The epidemiology of metatarsal fractures. Foot Ankle Int 2006;27(3):172-4.

5. Janne S, Rantanen J, Sakari O, Alanen J. Tension-Band Wiring for Fractures of the Fifth Metatarsal Located in the Junction of the Proximal Metaphysis and Diaphysis. The American Journal of Sports Medicine. 2006;34(3):476-80.

6. Torg JS. Fractures of the base of the fifth metatarsal distal to the tuberosity. Orthopedics. 1990;13(7):731-7.

7. Stewart IM. Jones' fracture: fracture of the base of the fifth metatarsal. Clin Orthop. 1960;16190-198.

8. Lawrence SJ, Botte MJ. Jones' fractures and related fractures of the proximal fifth metatarsal. Foot Ankle. 1993;14(6):358-65.

9. Mehlhorn AT, Zwingmann J, Hirschmüller A, Südkamp NP, Schmal H. Radiographic classification for fractures of the fifth metatarsal base. Skeletal Radiol. 2014;43(4):467-74.

10. Biz C, Zamperetti M, Gasparella A, Dalmau-Pastor M, Corradin M, de Guttry G, Ruggieri P. Early radiographic and clinical outcomes of minimally displaced proximal fifth metatarsal fractures: cast vs functional bandage. Muscles, Ligaments and Tendons Journal. 2017;7(3):532-540.

11. Bianchi S, Bortolotto C, Draghi F. Os peroneum imaging: normal appearance and pathological findings. Insights Imaging. 2016;8(1):59-68.

12. Imre N, Kocabiyik N, Sanal HT, Uysal M, Ozan H, Yazar F. The peroneus brevis tendon at its insertion site on fifth 122 metatarsal bone. Foot Ankle Surg. 2016;22(1):41-5.

13. Ferran NA, Oliva F, Maffulli N. Ankle instability. Sports Med Arthrosc Rev. 2009;17(2):139-45.

14. Oliva F, Del Frate D, Ferran NA, Maffulli N. Peroneal tendons subluxation. Sports Med Arthrosc Rev. 2009;17(2):105-11.

15. Cheung CH, Lui TH. Proximal Fifth Metatarsal Fractures: Anatomy, Classification, Treatment and Complications. Arch Trauma Res. 2016;5(4):e33298.

16. Rammelt S, Heineck J, Zwipp H. Metatarsal fractures. Injury. 2004; 35(2):SB77-SB86.

17. Lee KT, Park YU, Young KW, Kim JS, Kim JB. Surgical results of 5 th metatarsal stress fracture using modified tension band wiring. Knee Surg Sports Traumatol Arthrosc. 2011;19(5):853-7.

18. Padulo J, Oliva F, Frizziero A, Maffulli N. Muscles, Ligaments and Tendons Journal - Basic principles and recom mendations in clinical and field Science Research: 2018 update. MLTJ 2018; 8(3): 305 - 307 